\title{
Stochastic Production in a Regulated Fishery: \\ The Importance of Risk Considerations
}

\author{
Phoebe Koundouri ${ }^{1}$ \\ Department of Economics, School of Business, University of Reading \\ Department of Economics and CESERGE, University College London
}

Marita Laukkanen

Academy of Finland and MTT Agrifood Research Finland

\section{Introduction}

Variability of output, often referred to as production risk, is inherent in marine fisheries susceptible to changing environmental conditions. Risk plays an important role in input use decisions. Input quantities not only determine the volume of output produced but some of these inputs also affect the extent of production risk. In this paper we address the implications of production risk for controlling fishing effort in a regulated fishery in a framework where fishers maximize expected utility of profit. We focus on controlling effort through season closures that limit the number of days the fishery is open to harvest each year.

Risk attitudes of economic agents are an important factor in input allocation decisions and hence in output produced (see, for example, Stiglitz (1974), Just and Pope (1978), Antle (1987)). Risk considerations are necessary in the analysis of the fishery sector as there exist a number of possible cases where policy formulation should consider not only the marginal contribution of input use to the mean of output, but also the marginal reduction in the variance or higher moments of output. To this end, we investigate fishers' behaviour toward production risk, their input choices and the respective effects on output, and discuss the policy implications of production risk for

\footnotetext{
${ }^{1}$ The authors wish to thank Sean Pascoe for making the data available and Celine Nauges for comments and suggestions regarding the applied section of the paper. The usual disclaimer applies.
} 
regulating a fishery through controlling season length. In particular we consider fishers' capacity choice and fishing effort, approximated by the number of days at sea.

Despite the uncertainty inherent to the fishing industry, the theoretical articles that address the choice of fishing effort and capital inputs in fisheries largely assume away uncertainty. Gordon (1954), Scott (1955) and others have shown that open access to fisheries results in effort levels that result in overharvesting and dissipation of economic rents. Clark, Clarke and Munro (1979) were the first to explicitly account for optimal investment in fleet capital. McKelvey $(1985,1986)$ studied the capital investment decisions of an individual fisher operating in an open access fishery, and showed that open access results in excessive capital investment as compared to the optimal management scenario. Homans and Wilen (1997) studied the regulated open access case, where TACs are in place in order to conserve the fish stock but no effective attempts are made to control the fleet size. They showed that economic overfishing will emerge in the regulated open access fishery as well.

The issue of overfishing and overcapitalisation demonstrated by the above research is caused by misguided incentives arising from the absence of well-defined property rights. The problem could thus be expected to persist in models explicitly including uncertainty in the analysis of the regulator's and individual fishers' optimal effort and capital choice. However the extent of the discrepancy between the individually and socially optimal choices may depend on the uncertainty characterizing the industry as well as on the fishers' risk preferences. In order to steer fisheries towards efficient input use, policies aiming at controlling fishing effort or fishing capacity should take into account the uncertainty inherent to fisheries, fishers' risk preferences and the effect of controls on both expected profit and on higher moments of profits.

Individual transferable quotas have been shown to be an optimal instrument for regulating fisheries in that they effectively define property rights and thereby correct the incentives of individual fishers (Clark 1980, Anderson 1992). In spite of this suboptimal instruments such as season closures, input restrictions and limited entry restrictions are used in many fisheries. In addition to being an economically suboptimal instrument, season closures add risk in the fishery in that openings may occur during extreme weather conditions, such as storms. As season closures are regardless of these shortcomings 
widely used as a regulatory instrument, we focus on the effect of season closures on fishers' input choice when fishers' production risk behaviour is explicitly accounted for.

Early studies involving the estimation of production functions in order to establish a relationship between inputs and outputs in fisheries include, among others, Hannesson (1983), Squires (1987), Pascoe and Robinson (1998) and Campbell and Lindner (1990). More recently, interest in technical efficiency has driven a shift towards the estimation of production frontiers. ${ }^{1}$ These were estimated using Data Envelopment Analysis (DAE), which allows the study of technical and allocative inefficiency. Relevant studies include Pascoe, Coglan and Mardle (2001), Tingley, Pascoe and Mardle (2003) and Vestergaard, and Squires and Kirkley (2003). However, as DAE is non-parametric, it is sensitive to random error, and also does not provide estimates of the impact of individual inputs on the level of outputs, or the relationship between the outputs themselves. To overcome these shortcomings, a number of papers estimate stochastic production frontiers for fisheries; see for example, Kirkley, Squires and Strand (1995, 1998), Grafton, Squires and Fox (2000) and Pascoe and Coglan (2002). Stochastic production frontiers account for the possible influence of data noise, arising from measurement error or model misspecification, upon the shape and positioning of the frontier. Estimating these frontiers involves the specification of a frontier function with an error term with two components: a symmetric error to account for noise and an asymmetric error to account for inefficiency. All of these studies neglect uncertainty and risk. ${ }^{2}$

In the general production function literature the impact of the choice of inputs on production risk has been studied more extensively. The traditional theoretical studies implicitly assume that inputs increase risk. Examples of such studies are Stiglitz (1974), Batra (1974) and Bardhan (1977). These studies utilised multiplicative stochastic specifications, which are restrictive in the sense that inputs that marginally reduce risk are not allowed. Just and Pope (1978) identified this limitation and proposed a more general stochastic specification of the production function. Their model includes two general functions: one which specifies the effects of inputs on the mean of output, and another one which determines the effects on its variance, thus allowing inputs to be either riskincreasing or risk-decreasing. 
While Just and Pope's model is a generalization of the traditional model in that it does not restrict the effects of inputs on the variance to be related to the mean, Antle (1983, 1987) has shown that it does restrict the effects of inputs across the second and higher moments in exactly the way traditional econometric models do across all moments. Thus Antle's departure point was to establish a set of less restrictive general conditions under which standard econometric techniques can be used to identify and estimate risk attitude parameters as part of a structural econometric model. More specifically, Antle's moment-based approach begins with a general parameterisation of the moments of the probability distribution of output, which allows the identification of risk parameters for more flexible representations of output distributions. Moreover, Antle's approach places the emphasis on the distribution of risk attitudes in the population, which constitutes a departure from existing literature which focuses on measurement of the risk attitudes of the individual producer (see for example Hazell, 1982; Pope, 1982; and Binswanger, 1982).

Love and Buccola (1991, 1999) also proposed an extension of Just and Pope’s model including producers' attitude toward risk in the model. They assumed an implicit form of the utility function and considered producers' risk preferences in a joint analysis of input allocation and output supply decisions. Just and Pope’s work has also been extended in a series of studies on salmon farming. Kumbhakar (2002a) examines joint estimation of production and risk preference functions in the presence of production risk and output price uncertainty, using a quadratic specification for the production and utility functions. ${ }^{3}$ In another recent study by Kumbhakar (2002b) risk preference functions are derived without assuming an explicit form of the utility function and any distribution of the error term representing production risk. Two sources of risk, namely production uncertainty and technical efficiency, are considered. Kumbhakar and Tveterås (2003) use a system approach to simultaneously estimate production risk, risk preferences and firm heterogeneity. Kumbhakar and Tsionas (2002) use a nonparametric approach to estimate the production function, the risk function and risk preference function associated with production risk, thereby avoiding the need to specify a functional form for either the production or risk functions. ${ }^{4}$ 
All of the above studies use the Just and Pope specification in the sense that they do not allow for the identification of the effect of inputs on the higher moments of output. In this study instead we apply Antle's $(1983,1987)$ moment based approach, which enables estimation of the stochastic production function and fishers' risk attitudes without any ad hoc specification of the form of the risk preferences. We study stochastic production, input choice and fishers' risk attitudes in the North Sea Fishery. The extensive requirements in terms of functional form specification of the various distributions (stochastic production function, risk function, utility function under risk) involved in the analytical solution of the model lead us to attempt an empirical approximation to this model. Antle's flexible moment-based approach readily lends itself to estimating the empirical approximation.

The chapter is organized as follows. In section 2 we present the underlying model of fishers' behaviour under risk and discuss implications of risk aversion for policies that regulate inputs. The empirical model is described in section 3 . The model is applied to an unbalanced panel from the North Sea Fishery. The relevant data-set is described in section 4 and estimation results in terms of derived input-specific risk attitude characteristics (absolute Arrow-Pratt and down-side risk aversion coefficients and risk premium) are presented in section 5. Section 6 concludes the paper by discussing the impact of regulating inputs in a stochastic fishery in terms of input use and moments of profit, and the policy implications of such regulations.

\section{Theoretical Model: Fishers’ Behaviour under Risk.}

In this section we analyse the impact of season closures on the production decisions of a fisher operating in a risky environment. The model of the fishery we employ is necessarily a seasonal one. We follow Homans and Wilen (1997) and assume that vessel capital is non-malleable only on an intra-seasonal basis. ${ }^{5}$ Our focus here is on inputs whose choice and mixture may be modified by the fisher on a seasonal basis in order to hedge against production risk. Fishers are assumed price-takers, so that a modification in their input allocation decision will affect neither output nor input prices. 
Assume a management authority regulates the fishery and limits season length in the fishery. An economically optimal management strategy would entail choosing both the capital utilization and the resource investment policy simultaneously in order to maximize the expected utility of harvest over time. As long as property rights to the resource stock are not well defined, individual fishers have an incentive to expend effort in excess of the socially optimal levels. Season closures are used to limit effort in fisheries even though they have been shown to be inefficient in economic literature (see for example Clark 1990, Homans and Wilen 1997). In reality season length is often limited based on biological stock conservation objectives rather than economic considerations. Neglecting risk consequences may have unforeseen consequences both in terms of meeting the conservation goals of regulations and the economic performance of the industry.

An important aspect of our framework is that from the fishers' point of view the season length restriction is exogenous, so that once it is chosen, fishers decide on their production plans considering the season length as given. Both problems (choice of season length and decision on the level of production) are thus completely separated. This is because the management authority's criterion is based upon the whole resource stock and the entire fishing fleet, whereas each fisher only considers his individual expected utility and is too small to influence the agency's decision.

A key ingredient to assessing accurately the performance of such resource management policy is naturally studying the fishers' input choices and their effect on harvest under such a policy. This requires first, an adequate representation of the technology, but also of fishers preferences towards risk.

It is well known that ignoring possible distortions in production decisions due to risk aversion can lead to misleading results (Just and Pope, 1978; Aigner et al., 1977; Griffiths and Anderson, 1982). When production risk originating for example from climatic or ecological conditions is likely to be significant, producers may hedge against risk by modifying their input choices. Stochastic factors such as extreme weather conditions and variation in the size and distribution of the fish stock make the production 
process in marine capture fisheries risky. There is however considerable scope for controlling the level of output risk through input quantities. For example the effect of labour quality such as crew skill and experience may be important, since production outcomes depend on measures taken by the crew as a response to changing weather conditions and other environmental variation. Further large vessels are less susceptible to bad weather.

\section{The production model}

In this section, the basic representative agent production model under risk is developed. As noted above, we assume an exogenously-given season length whose determination is not detailed here.

Let $p$ denote output price for a single composite output, $f($.$) is the production function,$ $X$ is the $\mathrm{K}$ vector of inputs, and $r$ is the corresponding vector of unit input prices. We approximate fishing effort by days at sea. The season length restriction is directed towards this single input. We denote days at sea by $X_{D}$ with associated unit price $r_{D}$. We then have $X^{\prime}=\left(X_{1}, X_{2}, \ldots, X_{K-1}, X_{D}\right)$ and $r^{\prime}=\left(r_{1}, r_{2}, \ldots, r_{K-1}, r_{D}\right)$. The restriction imposed on $X_{D}$ is written

$$
X_{D} \leq \bar{X}_{D}
$$

where $\bar{X}_{D}$ is a restriction in absolute terms. We assume that there exists a single source of risk affecting production yield, denoted $\varepsilon$, whose distribution $G($.$) is not affected by$ fisher's actions (weather conditions and the like). In addition, we assume prices $p$ and $r$ to be non random, so that the only source of risk is production risk through the random variable $\varepsilon$. Let us suppose further that $f($.$) is continuous and twice differentiable. The$ representative agent's problem is to maximize expected profit if she is risk-neutral, or to maximize the expected utility of profit if she is risk-averse, subject to condition [1]. In the latter case, the agent's problem is 
$\operatorname{Max}_{X} \mathrm{E}[U(\pi)]=\operatorname{Max}_{X} \int\left[U\left(p f(\varepsilon, X)-r^{\prime} X\right)\right] d G(\varepsilon)+\lambda\left(\bar{X}_{D}-X_{D}\right)$,

where $\mathrm{U}($.$) is the Von Neuman-Morgenstern utility function and \lambda$ is the Lagrange multiplier associated with [1]. The optimal solution for action $X$ would then depend upon $(p, r)$ and on the shape of functions $U(),. f($.$) and G($.$) . The first-order condition$ associated with this problem for the fishing effort represented by days at sea $X_{D}$ is:

$$
\begin{aligned}
& \mathrm{E}\left[r_{\mathrm{D}} \times U^{\prime}\right]=\mathrm{E}\left[p \frac{\partial f(\varepsilon, X)}{\partial X_{\mathrm{D}}} \times U^{\prime}\right]-\lambda \\
& \Leftrightarrow \frac{r_{D}+\lambda / \mathrm{E}\left(U^{\prime}\right)}{p}=E\left(\frac{\partial f(\varepsilon, \mathrm{X})}{\partial X_{D}}\right)+\frac{\operatorname{cov}\left(U^{\prime}, \partial f(\varepsilon, X) / \partial X_{\mathrm{D}}\right)}{\mathrm{E}\left(U^{\prime}\right)},
\end{aligned}
$$

because $p$ and $r_{D}$ are not random, and where $U^{\prime}=\partial U(\pi) / \partial \pi$. It is apparent that the shape of the utility function (whose curvature is increasing with the degree of absolute risk aversion) will determine the magnitude of the departure from the risk-neutrality case. For a risk-neutral fisher, the price ratio under the season closure policy, $(1 / p)\left[r_{D}+\lambda / \mathrm{E}\left(U^{\prime}\right)\right]$ equals the expected marginal productivity of $X_{D}$. When the fisher is risk averse, the second term in the right-hand side of [3] is different from 0 , and measures deviations from the risk-neutrality case. More precisely, this term is proportional and has the opposite sign, to the marginal risk premium with respect to $X_{D}$. If the latter is risk increasing, the marginal risk premium increases with $X_{D}$ and the desired level of that input decreases, all other things being equal.

\section{Empirical Model: Assessing Risk Attitudes}


In principle, solving Equation [3] for $X_{D}$ yields the equilibrium fishing effort in terms of $p, r, \bar{X}_{C}$ and $\lambda$. However, the problem is empirically difficult. In addition to the choice of production function specification, the distribution of $\varepsilon$ needs to be known and the agent's preferences need to be specified through the utility function. We thus choose a flexible approach that has the advantage of requiring only information on profit, price and input quantities. The key feature of this approach is to note that the solution to the fisher's problem can be written as a function of input levels alone. More precisely, maximizing the expected utility of profit with respect to any input, subject to the season length restriction, is equivalent to maximizing a function of moments of the distribution of $\varepsilon$, those moments having themselves $X$ as an argument. There is no loss of generality here, because such function of the moments, denoted $F($.$) , is completely unspecified.$ The fisher's program becomes:

$\operatorname{Max}_{X} \mathrm{E}[U(\pi)]=F\left[\mu_{1}(X), \mu_{2}(X), \ldots, \mu_{m}(X)\right]$ subject to $X_{D} \leq \bar{X}_{D}$, where $\mu_{j}, j=1,2, \ldots, m$ is the $m^{\text {th }}$ moment of profit.

Based on the expression above, Antle $(1983,1987)$ proposes a moment-based approach to estimate risk-attitude parameters of a population of producers. Focusing on the population instead of focusing on each individual agent has two main advantages. It avoids any problem of aggregation of individuals and allows the identification of the riskattitude parameters from a cross-sectional dataset. However, this approach relies on some assumptions. First, the agent solves a single-period maximisation program in which inputs are predetermined variables. Second, all agents harvest with similar technology. Below, this stochastic technology is represented by the corresponding distribution of profit, which amounts to assuming that the same profit distribution applies to each fisher and that all fishers form the same expectations. We now describe more precisely Antle's method. From the first order condition, in matrix form:

$$
\frac{\partial \mu_{1}(X)}{\partial X}=(-1 / 2 !) \frac{\partial \mu_{2}(X)}{\partial X} \times \frac{\partial F(X) / \partial \mu_{2}(X)}{\partial F(X) / \partial \mu_{1}(X)}-(1 / 3 !) \frac{\partial \mu_{3}(X)}{\partial X} \times \frac{\partial F(X) / \partial \mu_{3}(X)}{\partial F(X) / \partial \mu_{1}(X)}
$$


$-\cdots-(-1 / m !) \frac{\partial \mu_{m}(X)}{\partial X} \times \frac{\partial F(X) / \partial \mu_{m}(X)}{\partial F(X) / \partial \mu_{1}(X)}$.

As before we index the inputs used in harvesting by $k=1, \ldots, K$ and we denote by $\alpha_{j k}$ the expression $\left(\partial F(X) / \partial \mu_{j}(X)\right) /\left(\partial F(X) / \partial \mu_{1}(X)\right) . \quad \alpha_{j k}, \quad(j=2, \ldots, m)$ represents the $j^{\text {th }}$ average population risk attitude parameter related to input $k$. For each input $k$, we will thus have $(m-1)$ unknown parameters. Each of the $K$ equations described below will be estimated separately.

$$
\frac{\partial \mu_{1}(X)}{\partial X_{k}}=-\alpha_{2 k} \times(1 / 2 !) \frac{\partial \mu_{2}(X)}{\partial X_{k}}-\alpha_{3 k} \times(1 / 3 !) \frac{\partial \mu_{3}(X)}{\partial X_{k}}-\cdots-\alpha_{m k} \times(1 / m !) \frac{\partial \mu_{m}(X)}{\partial X_{k}}
$$

The marginal contribution of input $k$ to the expected profit is given by $\partial \mu_{1}(X) / \partial X_{k}$, which is written as a linear combination of the marginal contributions of input $k$ to the other moments (variance: $\partial \mu_{2}(X) / \partial X_{k}$, skewness: $\left.\partial \mu_{3}(X) / \partial X_{k}, \ldots\right) . \alpha_{m k}$ measures the "weight" attributed by the fisher to the $m^{\text {th }}$ moment of his profit distribution. The analysis is made input by input because each input contributes in a different manner to the moments of the profit distribution. In general, we expect that all inputs increase the expected profit but, for the second and higher-order moments, we can find risk-increasing as well as risk-decreasing inputs.

The following model will be estimated for each input $k:^{6}$

$$
\frac{\partial \mu_{1}(X)}{\partial X_{k}}=\theta_{1 k}+\theta_{2 k} \frac{\partial \mu_{2}(X)}{\partial X_{k}}+\theta_{3 k} \frac{\partial \mu_{3}(X)}{\partial X_{k}}+\cdots+\theta_{m k} \frac{\partial \mu_{m}(X)}{\partial X_{k}}+u_{k}
$$

where $\theta_{2 k}=-\alpha_{2 k} \times(1 / 2 !), \theta_{3 k}=-\alpha_{3 k} \times(1 / 3 !), \ldots, \theta_{m k}=-\alpha_{m k} \times(1 / m !)$ and $u_{k}$ is the usual econometric error term. A nice feature of this model is that the parameters $\theta_{2 k}$ and $\theta_{3 k}$ 
are directly interpretable as Arrow-Pratt and down-side risk aversion coefficients respectively. Arrow-Pratt $(A P)$ absolute risk aversion coefficient is defined by:

$$
A P_{k}=-\frac{E\left(U^{\prime \prime}(\pi)\right)}{E\left(U^{\prime}(\pi)\right)} \cong-\frac{\partial F(X) / \partial \mu_{2}(X)}{\partial F(X) / \partial \mu_{1}(X)}=2 \theta_{2 k}
$$

A positive $A P$ coefficient means that the fisher is risk-averse. Down-side (DS) risk aversion is measured by:

$$
D S_{k}=\frac{E\left(U^{\prime \prime \prime}(\pi)\right)}{E\left(U^{\prime}(\pi)\right)} \cong \frac{\partial F(X) / \partial \mu_{3}(X)}{\partial F(X) / \partial \mu_{1}(X)}=-6 \theta_{3 k}
$$

A positive DS coefficient means that the fisher is averse to down-side risk. ${ }^{7} A P$ and $D S$ coefficients can then be used to compute the risk premium $R P$. Assuming that the fisher is concerned about the first three moments of the distribution only, we have $R P=\mu_{2} \frac{A P_{k}}{2}-\mu_{3} \frac{D S_{k}}{6}$ for each $k$, where $\mu_{2}$ and $\mu_{3}$ are respectively a measure of the second- and third-order moments of the distribution. $R P_{k} \succ 0$ would mean that the fisher is characterized by a positive willingness to pay to be insured against the risk associated with the use of input $k$. Coefficients $\alpha_{2 k}$ and $\alpha_{3 k}$, directly related to $A P_{k}$ and $D S_{k}$, can also be interpreted as a measure of the marginal contribution of each moment to the risk premium.

\section{Description of the Data-Set: The North Sea Fishery}

The North Sea is the major fishing area in European Community waters. Commercial activity in the region is mostly undertaken by fishermen from the UK, Denmark, the Netherlands, France, Germany, Belgium and Norway. Transboundary stocks are shared between the EU and Norway. The total value of the allowable catch in 1999 was estimated to be about 1.5 billion Euro. This is an underestimate of the true value of 
landings as the guide prices are generally lower than market prices. However, it provides an indication of the order of magnitude of the value of the fishery.

This study focuses on two main fleet segments that make up the majority of the UK North Sea fleet; one composed of mobile and the other composed of static vessels. Most of the stocks exploited by the fleet are heavily over-fished. In addition, the fishery has been targeted for decommissioning as it is considered to have considerable excess capacity. Fleet size has been almost halved between 1994 and 2000 as a result of the reduced North Sea quotas, pushing some boats into the English Channel and/or Celtic Sea, and decommissioning.

Despite being subject to quota controls, the quotas were not binding over the period examined. Since the introduction of the FQAs in 1999, the only binding quotas for North Sea species were for saithe and sole in 2000. For most species, quota uptake ranged between 70 and 90 per cent (DEFRA). An analysis of the available beam trawl logbook and quota allocation data for 2000 found that over 75 per cent of the vessels did not fill their quota allocation, with the remainder exceeding the allocation (presumably through quota leasing). Given the apparent abundance of quota and the apparent effectiveness of the quota leasing market, it was assumed for the purposes of this study that the quotas were not effectively constraining output.

Logbook production data and boat characteristics information from the central fleet registry for the trawlers operating in the North Sea were used in the analysis. The data is an unbalanced panel, including the following years: 1996, 1997, 2000, 2001 for both, the static and mobile segments of the fleet. Mobile gears include beam, dredge, otter and pelagic gears, while static gears include pots, nets and lines. Tables 1 and 2 present the relevant descriptive statistics.

Table 1. Descriptive Statistics of Variables: Mobile Vessels

\begin{tabular}{lll}
\hline Variable & Mean & Standard Deviation \\
\hline
\end{tabular}




\begin{tabular}{lll}
\hline Profit & $152,731.99$ & 145814.40 \\
Capital Value & 215372.18 & 222597.88 \\
Days at sea & 206.295 & 58.60 \\
Length of the vessel & 16.07 & 7.64 \\
Engine power (KW) & 177.67 & 170.58 \\
Age of the vessel & 19.71 & 12.59 \\
\hline
\end{tabular}

Number of Observations: 167

Table 2. Descriptive Statistics of Variables: Static Vessels

\begin{tabular}{lll}
\hline Variable & Mean & Standard Deviation \\
\hline Profit & $54,765.83$ & 90617.43 \\
Capital value & $52,119.46$ & 103764.36 \\
Days at sea & 178.25 & 65.72 \\
Length of the vessel & 9.38 & 4.07 \\
Engine power (KW) & 84.09 & 88.81 \\
Age of the vessel & 16 & 11.29 \\
\hline
\end{tabular}

Number of Observations: 269

Catches of the key species used in the construction of the profit variable incorporated into the model varied over the period examined, largely as a result of changes in stock conditions. Accounting for variations in stock abundance in fisheries production functions is generally undertaken through either the direct inclusion of the stock, or through the use of dummy variables. A particular problem exists for the use of stock indexes in multi-output production functions in that each stock measure relates directly to only one of the outputs, although indirectly it may affect the output of the others by affecting fishing patterns. A composite stock variable cannot effectively capture the stock changes of the different species, which do not follow a consistent pattern. To overcome these problems, the catches in each time period were normalized using the stock indexes, i.e., the catch in each time period was divided by the stock index in that 
time period. This allows the effects of changes in stock size on catch to be incorporated into the analysis, but imposes the implicit assumption of unitary output elasticity with respect to stock size. This assumption is most likely valid given the nature of the resources, in that they are widely dispersed, fairly uniform in density across their areas of distribution and exploited across their whole areas of distribution.

While several physical characteristics of vessels were available in the data set, e.g. length, age and engine power $(\mathrm{kW})$; only vessel capital value and days at the sea, the latter being the restricted input, were used in the production function estimation. Vessel age and engine power, were used as instruments in the last stage of the estimation procedure (2SLS). Vessel length was found to be highly correlated with engine power $(\mathrm{r}=0.94)$ and as a result was excluded from the model.

Since one of the requirements of Antle's approach is for the agents in the panel to have the same production technology, we apply the approach separately to the two samples of our panel: the one with the mobile gears and the one with the static gears.

\section{Econometric estimation and results}

\section{Measurement of risk-attitude parameters}

Following Antle (1987), we propose to estimate the sample-average risk-attitude parameters. As before, we distinguish between two groups of producers, fishers with mobile and static vessels, and two inputs, capital value and days at sea. We wish not to impose a priori the equality of risk-attitude parameters between the two different inputs. For each of the two groups, our estimation methodology is the following: first, we estimate the conditional expectation of profit using a quadratic functional form: total observed profit is regressed on all levels, squared and cross-products of inputs. The residuals of the latter regression are then used to compute conditional higher moments 
(variance and skewness), which are then regressed on all levels, squared and cross products of inputs.

Analytical expressions for derivatives of these moments with respect to each input are then computed. We finally fit a 2SLS equation of the estimated derivative of the expected profit on derivatives for higher moments for each input. Age of vessel and engine power, were used as instruments in the 2SLS estimation. The parameters associated with the second and third moment will respectively be denoted by $\theta_{2 k}$ and $\theta_{3 k}$ for each input $k$. Estimated parameters are then used to recover Arrow-Pratt $(A P)$ and down-side $(D S)$ risk aversion measures using the following relationships: $A P_{k} \cong 2 \hat{\theta}_{2 k}$ and $D S_{k} \cong-6 \hat{\theta}_{3 k}$; $k=1, \ldots, K$. These estimates are finally used to compute the average risk premium $\rho_{k}$ as a proportion of expected net returns for each input $k$, which is approximately equal to $\frac{\rho_{k}}{\mu_{1}}=\frac{\mu_{2} A P_{k}}{2 \mu_{1}}-\frac{\mu_{3} D S_{k}}{6 \mu_{1}}$ where $\mu_{2}$ and $\mu_{3}$ are respectively a measure of the second- and third-order moments of the distribution.

Estimation results for the sub-group of mobile vessels are found in Table 3. The Wald test rejects the null hypothesis of equal parameters between the effects of the choice of the two inputs. For both inputs, the parameters $\theta_{2}$ associated with the second moment (variance of profit) are positive and significant whereas the parameter linked to the third moment is negative and significant. Signs of these coefficients are "as expected", showing risk-aversion of mobile vessel producers (through both the Arrow-Pratt and down-side risk measures). The average relative risk-premium is similar across inputs, ranging from $17 \%$ (for capital) to $20 \%$ (for days at sea) of expected profit.

Table 3. Estimation of the risk-aversion measures: mobile vessels

\begin{tabular}{lcccc}
\hline & \multicolumn{2}{c}{ Capital Value } & \multicolumn{2}{c}{ Days at Sea } \\
\cline { 2 - 5 } & Est & Std Err & Est & Std Err \\
Constant & -0.0245 & 0.0715 & 0.1169 & 0.0729 \\
$\theta_{2 k}$ & 1.2726 & 0.4159 & 2.1143 & 0.2139
\end{tabular}




\begin{tabular}{lllll}
$\theta_{3 k}$ & -0.5222 & 0.6936 & -0.6346 & 0.8011 \\
\cline { 2 - 5 } & & & & \\
\cline { 2 - 5 }$A P$ & 2.55 & 0.83 & 4.23 & 0.43 \\
$D S$ & 3.13 & 4.16 & 3.81 & 4.81 \\
& \multicolumn{5}{c}{$17 \%$} \\
$R P$ & \multicolumn{3}{c}{$17 \%$} & \multicolumn{3}{c}{$17 \%$} \\
\hline
\end{tabular}

Wald test of parameters equality: 1771.0 (p-value: 0.0000).

Results for the static vessels sub-group are reported in Table 4. The Wald test rejects the null of parameter equality with regards to effects of these two inputs on expected profit. The parameter linked to the variance is positive and significant in both models. Thus, we get positive Arrow-Pratt risk aversion measures for both capital and days at sea inputs. Moreover the down-side risk measure is positive and significant for both inputs. The relative risk premia are lower in the static vessels group (7\% and 9\%, for capital and days at the sea, respectively) compared to the group of mobile vessels.

Table 4. Estimation of the risk-aversion measures: static vessels

\begin{tabular}{lcccc}
\hline & \multicolumn{2}{c}{ Capital Value } & \multicolumn{2}{c}{ Days at Sea } \\
\cline { 2 - 5 } & Est & Std Err & Est & Std Err \\
& & & & \\
constant & 0.1433 & 0.0400 & 0.1432 & 0.0222 \\
$\theta_{2 k}$ & 0.8595 & 0.1672 & 7.8820 & 0.7078 \\
$\theta_{3 k}$ & -1.4992 & 0.4680 & -20.7043 & 2.0907 \\
& & & & \\
& & & & \\
AP & 1.72 & 0.33 & 15.76 & 1.42 \\
DS & 9.00 & 2.81 & 124.23 & 12.54
\end{tabular}




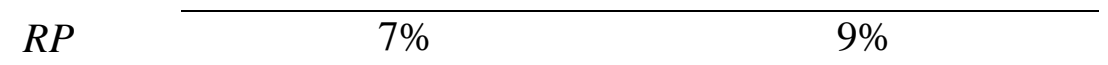

Wald test of parameters equality: 1570.3 (p-value: 0.0000).

We note that the constant term is not significant in either of the two models. We know that by definition we should not observe a significant constant term in the model linking the derivatives of moments of expected profit with respect to each input (see Equation [7]). A significant constant term indicates model misspecification, or that the input under consideration is inefficiently used and more precisely, a positive [resp. negative] sign means that the input under consideration is overused [resp. underused] in the sense that the expected marginal return is less [resp. greater] than the factor price. Our result indicates correct model specification and no production inefficiency.

\section{Policy Implications}

This paper dealt with estimation of the production technology and input choice decisions, when producer's face exogenous production risk. We estimated the production technology and risk preferences using Antle's flexible moment-based approach on data from the North Sea Fishery.

Our results show that, firstly, fishermen are risk averse. Secondly, failure to include risk aversion behavior in the characterization of the production function might bias parameter estimates and give wrong results on technological parameters. Thirdly, risk aversion behavior is translated in terms of risk premium, which is viewed as the implicit cost of private risk bearing. Risk premium as a percentage of mean profit is found to be different between mobile and static gears, with mobile gears exhibiting higher premia by $10 \%$ and $8 \%$ of profit, for capital and days at the sea inputs, respectively. Fishers using static gears (pots, lines and nets) involving smaller fixed costs often have other sources of income and are thus less susceptible to variation in the harvest yield. 
As shown in section 2 of the paper, if fishers are risk averse, the value of the marginal product of variable inputs exceeds their market price. This result might be used to argue (erroneously) that vessels are not efficient in allocating their variable inputs and that regulation regarding input choices is needed to enhance the economic performance of the fishery. Furthermore neglecting risk considerations when assessing impacts of regulation policies on input choices and expected harvest could provide misleading guidance to policy makers concerned about sustainable harvest levels. This is a significant piece of warning to all policy makers that contemplate regulation of stochastic production process in general, and fisheries, in particular.

\section{References}

Alvarez, A. and L. Orea, (2001). Different Approaches to Model Multi-Species Fisheries Using a Primal Approach', Efficiency Series Paper 3/2001, Department of Economics, University of Oviedo.

Anderson (1992). Consideration of the potential use of individual transferable quotas in US fisheries, Vol. 1: Overview Document, Report prepared for the National Oceanic and Atmospheric Administration (NOAA), 1992.

Antle, J., (1983). Testing the Stochastic Structure of Production: A Flexible MomentBased Approach. Journal of Business and Economic Statistics. 1, 192-201.

Antle, J., (1987). Econometric Estimation of Producers' Risk Attitudes. American Journal of Agricultural Economics. 509-522.

Bardhan, P., (1977). Variations in Forms of Tenancy in a Peasant Economy. Journal of Development Economy. 4, 105-118. 
Batra, R., (1974). Resource Allocation in a General Equilibrium Model of Production under Uncertainty. Journal of Economic Theory. 8, 50-63.

Bjørndal, T., Koundouri, P., and S. Pascoe (2003). Output substitution in multi-species trawl fisheries: implications for quota setting. American Journal of Agricultural Economics, (forthcoming).

Binswanger, H., 1982. Empirical Estimation and Use of Risk Preference: Discussion. American Journal of Agricultural Economics. 64, 391-393.

Campbell, H.F. and R.K. Lindner, (1990). The production of fishing effort and the economic performance of license limitation programmes. Land Economics. 66:55-66.

C. W. Clark, 1980. Towards a predictive model for the economic regulation of commercial fisheries. Canadian Journal of Fisheries and Aquatic Sciences, 37, 11111129.

Clark, C.W, F.H. Clarke and G.R. Munro, 1979, The optimal exploitation of renewable resource stocks: problems of irreversible investment, Econometrica, 47, 25-47.

Fousekis, P. "Distance vs. Ray Functions: An Application to the Inshore Fishery of Greece”. Marine Resource Econ. 17(2002):251-268.

Gordon, H.S. 1954, The economic theory of a common property resource: the fishery. Journal of Political Economy. 62, 124-142.

Hannesson, R., (1983). Bioeconomic production function in fisheries: Theoretical and Empirical analysis. Canadian Journal of Fisheries and Aquatic Science. 13(3):367-375.

Grafton, R. Q., D. Squires and K.J.Fox, (2000). Private Property and Economic Efficiency: A Study of a Common-Pool Resource, Journal of Law and Economics, 43(2): 679-713. 
Hazell, P., 1982. Application of Risk Preference Estimates in Firm-Household and Agricultural Sector Models. American Journal of Agricultural Economics. 64, 384-390.

Homans, R. and J. Wilen, 1997, A model of regulated open access resource use. Journal of Environmental Economics and Management. 32, 1-21.

Kirkley, J., D. Squires and I. Strand, (1995). Assessing Technical Efficiency in Commercial Fisheries: The Mid-Atlantic Sea Scallop Fishery, American Journal of Agricultural Economics, 77(4): 686-697.

Kirkley, J., D. Squires and I. Strand, (1998). Characterizing Managerial Skill and Technical Efficiency in a Fishery, Journal of Productivity Analysis, 9: 145-160.

Kumbhakar, S.C., 2002. Specification and Estimation of Production Risk, Risk Preferences and Technical Efficiency. American Journal of Agricultural Economics. 84, 8-22.

Kumbhakar, S. C., 2002. Risk Preference and Productivity Measurement Under Output Price Uncertainty. Empirical Economics. 27, 461-472.

Kumbhakar, S. C., and E., G., Tsionas, 2002. (Estimation of Production Risk and Risk Preference Function: A Nonparametric Approach. mimeo.

Kumbhakar, S. C. and R., Tveteras, 2003.Risk Preferences, Production Risk and Firm Heterogeneity. Scandinavian Journal of Economics. 105(2): 275-293.

Love, H.A., and S.T. Buccola, (1991). Joint Risk Preference-Technology Estimation with a Primal System. American Journal of Agricultural Economics. 73, 765-774. 
Love, H.A., and S.T. Buccola, (1999). Joint Risk Preference-Technology Estimation with a Primal System: Reply. American Journal of Agricultural Economics 81. 245-247.

McKelvey, R. (1985), Decentaralized regulation of a common property renewable resource industry with irreversible investment. Journal of Environmental Economics and Management. 12, 287-307.

McKelvey, R. (1986), Fur seal and blue whale: the bioeconomics of extinction, in M. Cohen (ed.), Applications of Control Theory in Ecology, Lecture Notes in Biomathematics, Heidelberg, Springer-Verlag, 57-82.

Just, R., and R. Pope, (1978). Stochastic Representation of Production Functions and Econometric Implications. Journal of Econometrics, 7, 67-86.

Just, R., and R. Pope, (1979). Production Function Estimation and Related Risk Considerations. American Journal of Agricultural Economics, 276-284.

Pascoe, S. and L. Coglan (2002) Contribution of unmeasurable factors to the efficiency of fishing vessels: an analysis of technical efficiency of fishing vessels in the English Channel. American Journal of Agricultural Economics 84(3) 45-57.

Pascoe, S., L. Coglan and S. Mardle. "Physical versus harvest based measures of capacity: the case of the UK vessel capacity unit system.” ICES J. Marine Sci. 58(2001): 1243-1252.

Pascoe, S. and C. Robinson, (1998). Input controls, input substitution and profit maximisation in the English Channel beam trawl fishery, Journal of Agricultural Economics, 49(1): 16-33. 
Pope, R., 1982. Empirical Estimation and Use of Risk Preference: An Appraisal of Estimation Methods That Use Actual Economic Decisions. American Journal of Agricultural Economics. 64, 376-383.

Scott (1955). The fishery: the objectives of sole ownership. Journal of Political Economy. 63, 116-124.

Squires, D. (1987). Fishing effort: Its testing, specification, and internal structure in fisheries economics and management. Journal of Environmental Economics and Management. 14(September):268-282.

Squires, D. and J. Kirkley, (1999). Skipper Skill and Panel Data in Fishing Industries, Canadian Journal of Fisheries and Aquatic Sciences, 56(11), 2011-2018.

Stiglitz, J., 1974. Incentives and Risk Sharing in Sharecropping. Review of Economic Studies 41, 219-255.

Tingley, D., S. Pascoe and S. Mardle. "Estimating capacity utilisation in multi-purpose, multi-metier fisheries.” Fish. Res. 63(2003): 121-134.

Vestergaard, N., D. Squires and J. Kirkley. "Measuring capacity and capacity utilization in fisheries: the case of the Danish Gill-net fleet”. Fish. Res. 60(2003): 357-368

\footnotetext{
${ }^{1}$ There are also theoretical reasons why the estimation of production frontiers has advantages over the estimation of production functions (see Kumbhakar, 2002).

${ }^{2}$ A common feature of these studies is the reliance on a single measure of output. However, unlike many other industries, fisheries are characterised by joint production. Multi-output distance functions in fisheries have been studied by Alvarez and Orea (2001), Fousekis (2002) and Bjørndal, Koundouri and Pascoe (2003), who examine the implications of output substitution in multispecies fisheries for quota setting.

${ }^{3}$ Kumbhakar considers an exogenous production shock rather than input dependent production risk in the sense of Just and Pope.
} 
${ }^{4}$ However, non-parametric estimations involve the selection of the kernel and bandwidth, which are not specification free.

${ }^{5}$ This assumption is a reasonable one for a fishery where vessels participating in harvest could be readily diverted to other fisheries.

${ }^{6}$ We should check that $\theta_{1 k}$ is not significantly different from zero in each model.

${ }^{7}$ Down-side risk is concerned with asymmetric (skewed) statistical distributions of profit. 